\title{
Analysis on the Characteristics of Travel Vlog Video and Its Impact on Users' Travel Intention
}

\author{
Yingying Chen ${ }^{1}$, Zhaojuan $\mathrm{Guo}^{2}$, Qiuyue Pan $^{3, *}$ \\ ${ }^{123}$ Xiamen University of Technology College of Culture and Tourism \\ *Corresponding author.Email: 515615950@qq.com; qiuyuepan@sina.com
}

\begin{abstract}
Travel Vlog video has become an important channel for tourists to obtain tourism information, which affects the behaviour intention of the viewers. By using empirical analysis, this paper summarizes the video characteristics of travel Vlog videos and explores how these characteristics affect users' behavioural intention to travel. The research results show that vlogger's attractiveness, interactivity, perceived entertainment and perceived usefulness of travel Vlog videos have a significant positive impact on behavioural intention to travel. Based on this, some suggestions are put forward for vloggers to enhance their own attractiveness, enhance video interactivity, strengthen entertainment experience and deepen video connotation. The research conclusions of this paper have strong reference significance for tourism destination marketing and management work.
\end{abstract}

Keywords: Travel Vlog, Video feature, Tourist behavioural intention, Impact analysis

\section{INTRODUCTION}

The progress of network information technology and the development of social media platform have an important impact on people's information acquisition and decision-making behaviour. Along with the rise of all kinds of video media technology and platform, shooting and uploading video to network media platform has become popular behaviour, especially for post-90s and post-00 generation, Vlog has gradually become the most important way for them to record their life and express their personality. As an emerging video mode, Vlog, based on diversified two-way interaction. Vloggers would like to share their personal life in a scenario-based way and respond according to the viewer's barrage and comments, so that both sides of the communication can maintain a mutual communication relationship. In recent years, many Vlog vloggers are keen to share their travel experiences and feelings on social media, and present their travel content more vividly in the form of video Vlog. Most travel Vlog is based on the personal travel experience of netizens to shoot and upload, with strong attraction and high credibility, easy to cause interactive communication. This kind of video communication has revolutionized the traditional mode of tourism information communication to a great extent, and has brought about influences on the behavioural decisions of potential tourists, as well as challenges to the marketing and management of tourism destinations. It is necessary to analyse how travel Vlog influences users' intention to travel, so as to provide theoretical basis for understanding this new mode of travel communication, and then provide reference for relevant marketing management decisions.

\section{LITERATURE REVIEW AND RESEARCH HYPOTHESES}

\subsection{Literature Review}

\subsubsection{Travel Vlog Research}

With the rapid development of the Internet, many new social media platforms and new ways of travel sharing have emerged. Travel Vlog is a new way for tourists to share their travel experiences. It records the real travel stories that tourists' experiences during their travels and presents them in the form of videos ${ }^{[1]}$. Compared with text blogs, travel Vlog allows vloggers to shoot their own videos in their travel destinations and upload them to social media platforms to arouse heated debate and expand the audiences. Travel Vlog is usually conversational vlogs, which represents the vlogger's conversations in front of the camera and records of the surrounding things ${ }^{[2]}$. In summary, travel video Vlog is 
defined in this paper as the travel video generated by travellers who record the real stories they have experienced through their mobile phones or cameras, which can be diversified in form after certain processing.

As the main type of user-generated content, tourism Vlog is exerting an important influence on the travel decision-making behaviour of users, and has a profound impact on tourism marketing work. Related research showed that video marketing could affect tourists' behaviour intention more than other forms of marketing ${ }^{[3]}$. Travel Vlog, as the authentic comments generated by tourists after on-the-spot experiences in tourist destinations, has changed the traditional authoritative recommendation model of tourism. Each vlogger has different views on tourist destinations, thus stimulating the travel motivation of potential tourists. Based on the degree to which travellers trust vloggers, travel Vlog can influence travellers' purchasing decisions.

\subsubsection{Tourism Intention and Influencing Factors}

Tourism intention is a kind of attitude of tourists towards a destination ${ }^{[4]}$. Yong (2016) points out that traveling intention is an individual's tendency and possibility to travel a destination ${ }^{[5]}$. Tourists' behavioural intention can be divided into two types: travel intention and recommended intention. Travel intention includes initial travel intention and repeated travel intention. Although researchers have not formed a consistent definition of the intention to travel, travel intention and recommendation intention are usually used to measure the intention to travel. Among them, the first trip intention refers to the tourists have never been to a tourist destination and have the tendency to travel there. The intention to revisit refers to the tendency of tourists to return to a certain destination in the future. Recommendation intention refers to the willingness of tourists to recommend their family members or friends to travel to a tourist destination. This study also adopted such measurement method.

Tourism intention is an important process to realize tourism behaviour, which is produced by many factors. To identify the factors that affect the tourism intention is the premise to stimulate the motivation of tourism and promote the behaviour of tourism. Many scholars have also conducted in-depth studies on this issue and summarized some important factors, including destination image, tourists' perceived value and the degree of attachment to the place; emotional connection between potential travellers and their destinations; tourists' attitude to traveling behaviour ${ }^{[6-8]}$. With the development of the internet and social media, scholars have also paid attention to the influence of social media on travel intention ${ }^{[9]}$. Users' positive attitude towards the use of Weibo in tourist cities would enhanced the behavioural intention of tourists. On the contrary, Users' negative attitude towards the use of Weibo in tourist cities would weaken their behavioural intention of tourists.

Among the above factors, the image of the tourist destination is still the main influencing factor. Vlog plays an irreplaceable role in spreading the image of tourist destinations. With many mainstream social media platforms coming into the public view, the development of "We Media" platforms provides more opportunities and channels for tourists to share their travel status with others. Travel Vlog publishes these travel status generated videos on social media platforms. Compared with photos and traditional forms of publicity, it has a wider spread range. Travel Vlog has more attractive to fans, and can also better arouse the intention of potential tourists to travel. However, there are relatively few studies on travel Vlog which does not match the rise and development degree of Vlog practice. This study will analyse the characteristics of Vlog video and its influence on the intention to travel, which is an effective supplement to this research field. The conclusion of this study is also helpful for tourism destination marketing organizations to better understand the influence and influence mechanism of Vlog video, so as to provide a reference for marketing strategy decision-making.

\subsection{Research Hypotheses}

In this paper, the characteristics of tourism video Vlog are summarized into four dimensions of vlogger's attractiveness, interactivity, perceived entertainment and perceived usefulness, and the impact of these four dimensions on users' travel intention is analysed.

\subsubsection{Influence of Vlogger's Attractiveness on Users' Travel Intention}

Vlogger's attractiveness refers to the attractiveness of a vlogger to potential tourists in a travel Vlog, including the image and behavioural characteristics of the vlogger. Each vlogger's different definition and style of Vlog will have a certain impact on the uploading form, video focus, editing method and presentation method of Vlog itself, and bring different feelings to viewers, which will then have an impact on users' travel behaviour intention. The image of vloggers will affect the audience's first impression to the vloggers' personality charm, and personality shaping. Good images could establish a clear positioning for the audience, and often could better guide the audience. Therefore, a good vlogger's image and personal charm are more likely to have an impact on viewers. The following hypothesis was proposed in this study:

H1: Vlogger's attractiveness has a significant positive impact on users' travel intention. 


\subsubsection{Influence of Perceived Interaction on Users' Travel Intention.}

Perceived interactivity refers to the degree of interaction between users and an information system. In the emerging social media, the interaction between tourists and tourist destinations is not only the one-way information dissemination of tourist destinations through mass media, but also the two-way communication between tourists and tourist destinations. Tourists obtained information through mass social media platforms, gained experience in travel vlog, and could get other people's travel experience in comments and barrage of tourism experience. Ghose and Dou (1998) pointed out that there was a certain correlation between perceived interaction and user behaviour intention ${ }^{[10]}$. Our study supposes that the willingness of potential tourists to participate in the vlog of travel video will positively affect their travel intention. Therefore, the following hypothesis was proposed in this study:

$\mathrm{H} 2$ : Perceived interactivity has a significant positive influence on users' travel intention.

\subsubsection{Influence of Perceived Entertainment on Users' Travel Intention}

Perceived entertainment is a performance of psychological pleasure, which refers to the degree of fun perceived by individuals when they participate in an activity. Teoet.al. (1999) pointed out that perceived entertainment performance had a great influence on internet users' behavioral intention ${ }^{[11]}$. If the activity of viewing a travel vlog is an entertaining experience for the viewer and provides them with pastime to fill their leisure time, the viewer can become a potential tourist. In this study, perceived entertainment refers to the degree of entertainment that travel Vlog brings to potential tourists. Therefore, the following hypothesis was proposed in this study:

H3: Perceived entertainment has a significant positive effect on users' travel intention.

\subsubsection{Influence of Perceived Usefulness on Users' Travel Intention}

Perceived usefulness refers to the extent of users perceive the efficiency improvement which brought by the use of an information system [12]. Perceived usefulness had a great influence on tourists' behavioral intention ${ }^{[13]}$. In this study, perceived usefulness refers to the fact that potential tourists believe that the information conveyed in the travel Vlog will be helpful for their future visit to the tourist destination. Therefore, the following hypothesis was proposed in this study:
H4: Perceived usefulness has a significant positive impact on users' travel intention

\section{RESEARCH DESIGN AND DATA COLLECTION}

\subsection{Variable Design and Measurement}

This paper discusses the influence of travel vlog video characteristics on tourists' travel intention. The research variables are shown in tablel and table 2 . Research variables include video characteristics as independent variables and travel intention as dependent variables. Among them, video features include four dimensions: vlogger's attractiveness, perceived interactivity, perceived entertainment and perceived usefulness. Variables were measured with reference to established scales and were modified appropriately according to the characteristics of travel Vlog video. The following scales have been developed.

\subsection{Data Collection and Sample Description}

The survey objects are users who have watched travel Vlog on social media. In order to ensure the validity of the questionnaire, the following methods are adopted to screen the questionnaire: Firstly, in order to better ensure the validity of the questionnaire, the questionnaire is beginning with the question: 'have you watched the travel Vlog in the last three months?' As a filtering question, choose yes to continue to answer, the subsequent questions are valid. Secondly, after the questionnaire was collected, each questionnaire was screened, and all the questionnaires filled with incomplete or dishonest data were deleted. It was rejudged that the distribution and collection of questionnaires were mainly conducted through the questionnaire. A total of 207 questionnaires were collected, among which 193 were valid.

Among the effective samples, females accounted for $71 \%$ and males accounted for $29 \%$. In terms of age distribution, 21-30 years old accounted for the largest proportion, accounting for $72.5 \%$, followed by under 20 years old, and accounting for $13.5 \%$. This group is more sensitive to new things and more willing to contact travel Vlog videos. From the level of education, college graduate or bachelor degree was the main object, this survey accounted for $80.3 \%$, the proportion of high school and the following accounted for only about $4.7 \%$, showed that the respondents with higher levels of education. From the monthly salary, respondents disposable living expenses were mainly concentrated in the following 1500 , the related to this survey was given priority to with students. From the frequency of travel vlog viewing, $51.7 \%$ of the samples occasionally watched travel Vlog, and $32.9 \%$ of the respondents often watched travel Vlog, indicating that the 
respondents were familiar with travel Vlog. In terms of the biggest reason to watch travel Vlog, $40.1 \%$ of respondents wanted to know more information about tourist attractions and destinations, and $15.0 \%$ of the respondents watched because they like anchors. Therefore, it could be seen that vloggers had a great influence on travel Vlog.

Table 1.Study variables

\begin{tabular}{|l|l|l|}
\hline MODULE & VARIABLE & DEFINITION \\
\hline \multirow{3}{*}{$\begin{array}{l}\text { PREDICTOR } \\
\text { VARIABLE }\end{array}$} & $\begin{array}{l}\text { Vlogger's } \\
\text { attractiveness }\end{array}$ & $\begin{array}{l}\text { A travel vlogger can be enticed to watch a travel vlog based on what the traveler } \\
\text { thinks the vlogger is attracted. }\end{array}$ \\
\cline { 2 - 3 } & $\begin{array}{l}\text { Perceptual } \\
\text { interactivity }\end{array}$ & $\begin{array}{l}\text { Potential tourists' willingness to participate in the interaction when they watch } \\
\text { travel video Vlog. }\end{array}$ \\
\cline { 2 - 3 } & Perceived enjoyment & The level of entertainment that travel Vlog brings to potential travelers. \\
\cline { 2 - 3 } $\begin{array}{l}\text { DEPENDENT } \\
\text { VARIABLE }\end{array}$ & Willingness of travel & $\begin{array}{l}\text { The degree to which potential travelers feel that the information conveyed in the } \\
\text { travel Vlog is adequate to meet their information needs. }\end{array}$ \\
\hline
\end{tabular}

Table 2.Variable Measurement Scale

\begin{tabular}{|c|c|}
\hline MODULE & QUESTION \\
\hline \multirow{5}{*}{$\begin{array}{l}\text { VLOGGER'S } \\
\text { ATTRACTIVENESS }\end{array}$} & (1)The vlogger looks good \\
\hline & (2)The vlogger feels a lot like me \\
\hline & (3)The vlogger shares values that I identify with \\
\hline & (4)The vlogger's behavior is very similar to mine \\
\hline & (5)The vlogger and I have a lot in common \\
\hline \multirow{4}{*}{$\begin{array}{l}\text { PERCEPTUAL } \\
\text { INTERACTIVITY }\end{array}$} & (1)Happy to participate in interactive communication in travel vlog \\
\hline & (2)Questions may be answered when participating in the travel vlog interaction \\
\hline & (3)Facilitating travel options through interaction in travel vlog \\
\hline & (4)Interaction in the travel vlog deepens my understanding of the tourist city \\
\hline \multirow{5}{*}{$\begin{array}{l}\text { PERCEIVED } \\
\text { ENJOYMENT }\end{array}$} & (1)Watch travel vlog to enrich my free time \\
\hline & (2)Watch travel vlog because it's fun \\
\hline & (3)Watch travel vlog because it makes me feel very relaxed \\
\hline & (4)Watch travel vlog because it makes me feel cool \\
\hline & (5)Feel very excited when I watch travel vlog \\
\hline \multirow{4}{*}{$\begin{array}{l}\text { PERCEIVED } \\
\text { USEFULNESS }\end{array}$} & (1)Travel vlog makes me complete the travel choice more quickly \\
\hline & (2)Content in the travel vlog gives me a more comprehensive grasp of travel information \\
\hline & (3)Travel vlog make travel easier \\
\hline & (4)Get useful information by watching travel vlog \\
\hline \multirow{4}{*}{$\begin{array}{l}\text { WILLINGNESS } \\
\text { OF TRAVEL }\end{array}$} & (1)After watching the travel vlog, I became more interested in the city \\
\hline & (2)After watching the travel vlog, I want to visit the city \\
\hline & (3)After watching the travel vlog, I will go to the city again \\
\hline & (4)After watching the travel vlog, I will recommend friends and family to the city \\
\hline
\end{tabular}




\section{DATA ANALYSIS AND RESEARCH RESULTS}

\subsection{Reliability Analysis}

The reliability test is used to test the reliability and stability of the scale. The most common method in the attitude scale method is the alpha coefficient created by the Cronbach. For the evaluation of alpha coefficient, this paper adopts $\mathrm{Wu}$ Minglong's analysis standard, which requires that the lowest reliability coefficient should be above 0.50 , while the lowest reliability coefficient of the whole scale should be above 0.70 . In this paper, the reliability of the whole sample data and each variable item were tested. The $\alpha$ coefficient of the whole sample was 0.823 , which meant the overall consistency of the questionnaire was high. The Kronbach $\alpha$ coefficient of all variables were above 0.7 , and the Kronbach $\alpha$ coefficient of all variables were over 0.5 after the deletion of the item, which was not far from the $\alpha$ coefficient of the variables. The results proved the internal consistency of the subscale. No items needed to be deleted and the whole scale could be retained as a whole.

\subsection{Validity Analysis}

Validity refers to the extent to which measurement tools or means can accurately measure the item. In this paper, factor analysis method was used to test the scale validity. As shown in the table 3, KMO values of all variables were greater than 0.6 . These variables could be used for factor analysis and validity analysis had also passed Bartlett's test of sphericity. Therefore, scale data could prove that this scale was effective.

Table 3.Structural validity measurement scale

\begin{tabular}{|c|c|c|c|}
\hline Variable & $\begin{array}{l}\text { Question } \\
\text { Number }\end{array}$ & $\begin{array}{l}\text { Component } \\
\text { matrix }\end{array}$ & $\mathrm{KMO}$ \\
\hline \multirow{5}{*}{$\begin{array}{l}\text { Vlogger's } \\
\text { Attractiveness }\end{array}$} & $(1)$ & 0.834 & \multirow{5}{*}{0.791} \\
\hline & ( 2 ) & 0.821 & \\
\hline & ( 3 ) & 0.874 & \\
\hline & ( 4 ) & 0.813 & \\
\hline & $(5)$ & 0.792 & \\
\hline \multirow{4}{*}{$\begin{array}{l}\text { Perceptual } \\
\text { interactivity }\end{array}$} & $(1)$ & 0.731 & \multirow{4}{*}{0.681} \\
\hline & ( 2 ) & 0.623 & \\
\hline & ( 3 ) & 0.751 & \\
\hline & ( 4 ) & 0.615 & \\
\hline \multirow{3}{*}{$\begin{array}{l}\text { Perceived } \\
\text { enjoyment }\end{array}$} & ( 1 ) & 0.752 & \multirow{3}{*}{0.757} \\
\hline & $(2)$ & 0.884 & \\
\hline & ( 3 ) & 0.831 & \\
\hline
\end{tabular}

\begin{tabular}{|l|l|l|l|}
\hline \multirow{4}{*}{$\begin{array}{l}\text { Perceived } \\
\text { usefulness }\end{array}$} & $(4)$ & 0.884 & \multirow{4}{*}{0.813} \\
\cline { 2 - 3 } & $(5)$ & 0.893 & \\
\hline & $(1)$ & 0.792 & \\
\cline { 2 - 3 } & $(2)$ & 0.634 & \\
\cline { 2 - 3 } & $(3)$ & 0.721 & \\
\cline { 2 - 3 } & $(4)$ & 0.884 & \\
\hline \multirow{4}{*}{$\begin{array}{l}\text { Willingness of } \\
\text { travel }\end{array}$} & $(1)$ & 0.872 & \\
\cline { 2 - 3 } & $(2)$ & 0.845 & \\
\cline { 2 - 3 } & $(3)$ & 0.797 & \\
\cline { 2 - 3 } & $(4)$ & 0.613 & \\
\hline
\end{tabular}

\subsection{Correlation Analysis}

Pearson correlation coefficient is used to judge the overall correlation degree of data. The four travel Vlog characteristics of vlogger's attractiveness, perceived interactivity, perceived entertainment, and perceived usefulness were all significantly positively correlated with the intention of potential tourists after watching travel vlog video.

\subsection{Regression Analysis}

After proving the significant correlation between the variables in this study, the stepping-multiple regression method was adopted to finally determine the impact of the vlogger's attractiveness, perceived interactivity, perceived entertainment, perceived usefulness on users' intention to travel. The specific regression results were shown in Table 4. The overall goodness of fit of the regression results was 0.513 , indicating that the four characteristics of the travel Vlog could clearly explain the variation of $51.3 \%$. F value of the regression model was $14.13(\mathrm{P}<0.05)$, indicating the significance of its regression effect. In the regression model, each dimension has passed the significance test (Sig. values were all less than 0.01), and its standardized coefficients were all positive, indicating that the four travel Vlog characteristics of vlogger's attractiveness, interactivity, perceived entertainment and perceived usefulness had a significant positive impact on the travel intention of potential tourists. The D.W value of the model was 1.531, indicating that there was no serial correlation between the regression variables. The VIF value of each independent variable was less than 3 , indicating that there was no serious multicollinearity among multiple independent variables. Therefore, the overall regression model can be expressed as follows: after watching the travel Vlog, potential tourists' intention to travel $=0.241 \times$ vlogger's attractiveness $+0.251 \times$ perceived interactivity $+0.113 \times$ perceived entertainment $+0.352 \times$ perceived usefulness.

$\mathrm{H} 1, \mathrm{H} 2, \mathrm{H} 3$ and $\mathrm{H} 4$ were verified. 
Table 4. Regression analysis of characteristics of travel Vlog on users' intention to travel

\begin{tabular}{|c|c|c|c|c|c|}
\hline $\begin{array}{l}\text { Regression } \\
\text { model }\end{array}$ & $\begin{array}{c}\text { Adjusted } \\
\mathrm{R}^{2}\end{array}$ & $\mathrm{~F}$ & $\begin{array}{c}\text { Std. } \\
\text { Coeff. }\end{array}$ & Sig. & VIF \\
\hline Constants & \multirow{5}{*}{0.513} & \multirow{5}{*}{$\begin{array}{l}14.13 * \\
*\end{array}$} & -- & 0.000 & -- \\
\hline Vlogger's & & & 0.241 & 0.000 & 1.451 \\
\hline Perceptual & & & 0.251 & 0.000 & 2.461 \\
\hline Perceivedenjoym & & & 0.113 & 0.008 & 1.431 \\
\hline Perceived & & & 0.352 & 0.005 & 2.716 \\
\hline
\end{tabular}

\section{CONCLUSION}

\subsection{Research Conclusions}

The study showed that the four independent variables of travel Vlog, vlogger's attractiveness, perceived interactivity, perceived entertainment, perceived usefulness, were significantly correlated with users' intention to travel after viewing travel Vlog video, and travel Vlog characteristics had a positive and significant impact on users' intention to travel. Based on the results, the following research suggestions were put forward to provide reference for marketing management of tourism destinations using Vlog video marketing.

\subsection{Recommendations}

\subsubsection{Increasing Self-attractiveness of Vloggers}

The more attractive the vlogger, the more trust the potential tourists would have on the relevant recommendation of the vlogger, and the stronger their intention to travel after watching travel vlog video. As the public figures of the social media platform, vloggers had a greater influence on the potential tourists. A good vlogger image and personal charm are more likely to have an impact on the viewers. Therefore, vloggers should make efforts to improve their personal appeal when making videos, including but not limited to improving their personal image, creating positive values and actively looking for the breaking points of the videos. In addition, vloggers should create their own Vlog style, and a fixed video style could better attract viewers. From the perspective of tourism marketing, if a tourism destination needs to attract potential tourists through travel Vlog, it can start from vloggers, choose vloggers with large fans and strong attractiveness in travel Vlog. Invite them to travel to the destination and record their daily activities in the form of Vlog so as to promote tourism destination marketing.

\subsubsection{Enhancing Travel Vlog Interactivity}

As the more interactive the perception of travel vlog, the stronger the tendency of potential tourists to travel to places recommended by vloggers. Tourists obtain information through mass social media platforms, gain experience in travel vlog, and get other people's travel experiences in comments and barrage. Therefore, vlog vloggers should improve the interactivity of the video when making the video, so that potential tourists have the feeling of participating in the video shooting, and the willingness of potential tourists to participate in the interaction will have a positive impact on their willingness to travel. For example, vloggers can reply to viewers in comments and retweets, which can greatly enhance the interactivity of their travel Vlog.

\subsubsection{Enhancing the Sense of Entertainment Experience}

The more perceived entertainment a travel Vlog, the more likely a potential traveler will be to visit a site recommended by the vlogger. The rapid development of social media platforms has spawned more "We Media" people and provided users with a variety of information in a disguised way. If viewers fail to feel the entertainment in travel Vlog, from the perspective of tourism marketing, the behavior of turning viewers into potential tourists will not be successful. Therefore, enhancing the entertainment experience of travel Vlog has a significant impact on increasing video exposure and attention. If the activity of watching travel Vlog is entertaining for potential tourists and can provide them with distraction to fill their leisure time, then the willingness of potential tourists to travel will increase. Therefore, Vlog vloggers should make their videos more entertaining and make potential travelers feel that watching them can be unstressful and enjoyable. By combining with hot spots, they can increase the visibility of their videos. Through the use of pictorial content combined with video form, improve fans' attention; Vlog conveys entertainment and corresponding cultural content to fans to attract their attention. From the perspective of Vlog itself, Vlog can be more diverse in content. For example, a theme challenge can be choose in each city you visit, such as aimlessly walking around the city.

\subsubsection{Deepening the Connotation of Travel Vlog}

The stronger the perceived usefulness of the vlog, the greater the tendency of potential travelers want to travel to the places recommended by vloggers. Perceived usefulness refers to the degree to which 
potential tourists feel that video has improved their own experience and experience. If the cultural landscape, historical background and cultural connotation of some tourist attractions mentioned in the video can improve knowledge structure and cultural accomplishment for potential tourists, potential tourists are more likely to have the intention to travel. Therefore, Vlog vloggers should try to make their videos with abundant cultural meaning, increase the cultural content of their videos to attract more potential travelers. In addition, travel Vlog should be more life-oriented and detailed. Travel is not only about punching in at various scenic spots, but also about making Vlog itself have a sense of subversion.

\section{ACKNOWLEDGMENTS}

This research was funded by the Fujian Provincial Philosophy and Social Science Research Project (Grant No: JAS20320), Xiamen Humanities and Social Science Base Research Project (Grant No: [2021] B28) and Talent Support Program of Xiamen University of Technology (Grant No: XPDST19013, XPDST20001).

\section{REFERENCES}

[1] R. L. Peralta. How vlogging promotes a destination image: A narrative analysis of popular travel vlogs about the Philippines[J]. Place Branding and Public Diplomacy, vol. 15, 2019, pp. 244-256. DOI: https://doi.org/10.1057/s41254-019-00134-6

[2] O. Aran, J.I. Biel, Gatica-Perez D. Broadcasting oneself: Visual discovery of vloggingstyles[J]. IEEE Transactions on Multimedia, vol. 16, 2013, pp. 201-215. DOI: https://doi.org/ 10.1109/TMM.2013.2284893

[3] K.V.Vermes. Survey: One-third of advertising budget spent on video[EB/OL]. https://komarketing.com/industry-news/surveyone-third-advertising-budget-spent-video-362, 2018.

[4] W.C. Gartner. Image Formation Process [J]. Journal of Travel \&Tourism Marketing, vol.2,1994, pp.191-216.

DOI:https://doi.org/10.1300/J073v02n02_12

[5] ZHANG Yonggang. The influence of destination marketing media contacts on tourists' image cognition and travel intention-on the basis of investigation of tourists in Hangzhou [J]. Tourism Forum, vol.9, pp. 27-31. DOI:10.15962/j.cnki.tourismforum.201601005

[6] TU Hongwei, XIONG Linying, HUANG Yimin,GUO Gongxing. The Effect of Destination Image on Tourist Behavior Intention: An Explanation Based on the Emotion Appraisal Theory[J]. Tourism Tribune, vol. 32, 2017, pp. 32-
$41 \quad$ DOI: https://doi.org/10.3969/j.issn.10025006.2017.02.009

[7] Cheng T M, Lu C C. Destination image, novelty, hedonics, perceived value, and revisiting behavioral intention for Island tourism[J]. Asia Pacific Journal of Tourism Research, vol. 18, 2013, pp. 766-783. DOI: https://doi.org/10.1080/10941665.2012.697906

[8] LIU Wei LIN Derong. Influences of emotional connection and tourism city image on travel intentions [J]. Urban Problems, 2018, pp.95-103. DOI:https://doi.org/10.13239/j.bjsshkxy.cswt.1808 11

[9] HUANG Yuanhao, LAI Qifu, LING Feifei. Influence of Social Media on Tourists' Tourism intention-Empirical Research Based on Perception of Destination Image [J]. Resource Development \& Market. vol.34, 2018, pp. 1327-1331+1261. DOI: https://doi.org/10.3969/j.issn.10058141.2018.09.022

[10] S. Ghose, W. Dou. Interactive functions and their impacts on the appeal of Internet presence sites[J]. Journal of Advertising Research, vol.38, 1998, pp. 29-43. DOI: https://doi.org/10.1111/j.14682958.1998.tb00425.x

[11] T.S.H. Teo, V.K.G. Lim, R.Y.C Lai. Intrinsic and extrinsic motivation in internet usage [J]. Omega The International Journal of Management Science, 1999 (27):25-37. DOI: https://doi.org/10.1016/S0305-0483(98)00028-0

[12] F.D. Davis, R.P. Bagozzi, P.R. Warshaw. User acceptance of computer technology: A comparison of two theoretical models [J]. Management Science, vol.35,1989,pp.982-1003.DOI:

https://doi.org/10.1287/mnsc.35.8.982

[13] The Guiding Effect of Information Flow of Australian Tourism Website on Tourist Flow: Process, Intensity and Mechanism [J].Human Geography.Vol.22,2007,pp.94-99.DOI: https://doi.org/10.13959/j.issn.10032398.2007.05.020 